\title{
LITIGACIÓN INTERNACIONAL, FORUM NON CONVENIENS Y DAÑOS PUNITIVOS: EL CASO DEL ACCIDENTE AÉREO DE SPANAIR
}

\author{
INTERNATIONAL LITIGATION, FORUM NON CONVENIENS AND \\ PUNITIVE DAMAGES: THE CASE OF SPANAIR's AIR ACCIDENT
}

\author{
Isabel Lorente Martínez \\ Universidad de Murcia. España/Spain \\ isabel.lorente@icamur.org
}

Recibido/Received: 27/01/2015

Modificado/Modified: 16/04/2015

Aceptado/Accepted: 27/04/2015

\section{RESUMEN}

El 20 de agosto del año 2008 pasó a la historia de la aviación civil española como un día negro. Un avión de la compañía Spanair que despegaba desde el aeropuerto Madrid-Barajas con rumbo hacía Gran Canaria sufrió un fatal accidente al despegar. Sobrevivieron al mismo 18 personas, con heridas de diversa consideración y 154 fallecieron. Desde una perspectiva pragmática este trabajo intenta despejar dos incógnitas: la de la Competencia Judicial Internacional y la de la Ley estatal aplicable a un asunto donde hay una responsabilidad extracontractual derivada de un producto.

\section{PALABRAS CLAVE}

Daños extracontractuales, accidente aéreo, Convenio de la Haya 1973, Forum non Conveniens, Daños punitivos.

\section{SUMARIO}

I. Introducción. II. El caso Spanair. La larga lista de errores que desencadenaron en una gran tragedia. III. ¿Controversia nacional o conectada con más países? IV. Historia judicial del caso. La competencia judicial internacional. Especial atención a las figuras jurídicas de derecho anglosajón: Forum Non Conveniens y daños punitivos. V. Derecho aplicable y su problemática aplicación por los órganos jurisdiccionales españoles. Reglamento Roma II. Conclusiones. Bibliografía.

\begin{abstract}
On 20 August 2008 he moved to the history of Spanish civil aviation as a black day. A plane of Spanair taking off from Madrid-Barajas airport was due Gran Canaria suffered a fatal accident on takeoff. 18 people survived with injuries of varying degrees and 154 died. From a pragmatic perspective, this work tries to clear two unknowns: the International Judicial Jurisdiction and State Law applicable to a case where there is a contractual liability of a product.
\end{abstract}

\section{KEYWORDS}

Tort, plane crash, Hague Convention 1973, Forum non Conveniens, Punitive Damages.

\section{CONTENTS}

I. Introduction. II. The case Spanair. The long billiard cue lists of mistakes that they unleashed in a great tragedy. III. National controversy or connected with more countries? IV. Judicial history of the case. 
The judicial international Competence. Special attention to the juridical figures of Anglo-Saxon Law: Forum Non Conveniens and punitive damages. V. Applicable law and his problematic application for the jurisdictional Spanish organs. Rome II Regulation. VI. Conclusions. References.

\section{INTRODUCCIÓN}

1. El 20 de agosto del año 2008 se convirtió en un trágico día para el recuerdo de todos. Ese día el vuelo JK 5022 de la compañía Spanair, en ese momento parte del grupo SAS, partía de Madrid rumbo a Gran Canaria, era un aparato McDonnell Douglas MD-82 que inmediatamente después del despegue sufrió un fatal accidente. Fue el primer accidente mortal para Spanair en los 20 años de historia de la compañía, y el $14^{\circ}$ accidente mortal y la $24^{a}$ pérdida de aeronave que involucraba un avión de la serie MD-80. Fue el accidente de aviación de España con más fallecidos en 25 años. Fue la catástrofe aérea con más fallecidos en Europa Occidental desde el atentado del vuelo 103 de Pan Am de 1988 en el Reino Unido que mató a 270 personas. El avión alquilado por Spanair en 1999 y bautizado como "Sunbreeze", transportaba un total de 172 personas de las cuales 162 eran pasajeros, 4 tripulantes en movimiento y 6 tripulantes de vuelo. El resultado del accidente de Spanair se plasmó en 154 víctimas mortales y 18 heridos.

2. Según funcionarios del gobierno español, al menos 15 de los difuntos no eran españoles, incluyendo al menos cinco alemanes, dos franceses, un mauritano, un turco, un búlgaro, un gambiano, un italiano, un indonesio y dos brasileños. Entre los supervivientes hay al menos tres ciudadanos no españoles: un sueco, un finlandés y un boliviano.

\section{EL CASO SPANAIR. LA LARGA LISTA DE ERRORES QUE DESENCADENARON EN UNA GRAN TRAGEDIA}

3. Tras una ardua investigación que se centraba principalmente en el sensor de la temperatura del aire defectuoso, que inicialmente causó que el piloto volviera con el avión para el mantenimiento antes de su intento de despegue catastrófico. El mecánico simplemente desactivó el sensor porque la Lista de Equipo Mínimo (lista emitida por la compañía aérea especificando sistemas o equipos inoperativos que permiten el vuelo de la aeronave con determinados requisitos) del avión permitía dejarlo inoperativo.

4. El 10 de mayo de 2010 una de las cajas negras del avión siniestrado reveló que el avión regresó al hangar donde el mecánico desconectó el sistema de calefacción de la sonda RAT del relé 2-5 que a su vez gobernaba más sistemas del avión como el TOWS (Take Off Warning System o el Sistema de Sensación de Tierra Sistema: es un sistema de advertencia de configuración inadecuada para el despegue.) según el MEL (Minimal Equipment List). Tanto copiloto como piloto aprobaron la decisión del mecánico. Una vez dirección a la pista del accidente, el piloto comunica que es el tercer incidente que ha tenido en esa semana y el copiloto le dice que no quiere volver a volar con él. Antes del despegue el comandante cede el mando al copiloto que despega y en el momento suena una alarma 4 veces.

5. El informe interino A-032/2008(es un documento técnico que refleja el punto de vista de la Comisión de Investigación de Accidentes e Incidentes de Aviación Civil en relación con las circunstancias en que se produjo el evento objeto de la investigación) sobre el accidente del avión de Spanair muestra claramente como los accidentes son una larguísima 
cadena de errores. En este caso la cadena comienza desde el propio diseño de sistema del MD80, de los manuales, de las listas de comprobación, inconsistencias de las normativas y finalmente de los pilotos.

6. Fundamentalmente el accidente se produjo porque los pilotos no habían desplegado los flaps (los alerones posteriores de las alas) y los slats (los delanteros) necesarios para el despegue. A eso se sumó un fallo del TOWS (Take-off Warning System), el sistema de aviso de configuración de despegue, que no indicó con alarmas que el avión no estaba preparado para despegar.

7. El TOWS que debía haber hecho sonar la alarma al acelerar los motores, no funcionó. La razón era bien sencilla: estaba en "configuración de aire". Hubo un fallo de un relé, el R25, que es parte del sensor de tierra del tren de aterrizaje delantero: cuando se detecta presión en el amortiguador se pone en estado de "sensación de tierra", el TOWS sólo se activa en esta situación. Pero aquí hay varios problemas. Según los manuales y normativas, el TOWS sólo debía verificarse al inicio del primer vuelo del día (ya lo han cambiado después del accidente para que se haga antes de cada vuelo) y los TOWS de los MD80, 727 y 737-200 no tienen un sistema para alertar a los pilotos que no funciona correctamente. Aunque hagan la comprobación el sistema podría fallar hasta el momento del despegue y los pilotos no se darían cuenta.

8. ¿Por qué no tiene indicadores? Porque estaba considerado como un equipo de barrera adicional (backup), no como esencial, por lo que no tenía redundancia ni indicadores especiales (pero la otra contradicción es que está en la normativa como "Lista de Equipamiento Mínimo" -MEL- por lo que es indispensable para poder despegar).

9. Y el problema de la falta de redundancia es que por el fallo de un simple relé (el R2-5) hizo que fallase el TOWS y no había forma que los pilotos se enterasen. Pero hay otra triste paradoja relacionada con este fallo que podría haber dado pistas pero que no estaba explicado en ningún manual. Ese avión tuvo que abortar el despegue porque la sonda de medición de temperatura exterior (RAT Ram Air Temperature probe) estaba dando mediciones muy altas (hasta 105 grados). Eso ocurría porque se puso en marcha la calefacción estando en tierra cuando sólo debe funcionar en el aire, para evitar el congelamiento.

10. ¿Por qué se encendió en tierra? Porque también depende de la misma configuración de vuelo o tierra que depende el TOWS. Este mismo avión había tenido ya varias averías de ese tipo (eran difíciles de ver, más aún con el fallo intermitente del R2-5). Tendría que haber dado una pista de que el sistema de sensación de tierra estaba fallando, pero no estaba indicado en ningún manual. Por lo tanto, fue una conjunción entre problemas de ingeniería de sistemas tan complejos con interacciones humanas, que son las que finalmente ponen en funcionamiento ese complicado sistema de navegación aérea.

11. En navegación aérea, la ingeniería debe suplir cualquier olvido humano. Y para ello Boeing dispuso el TOWS, la alarma sonora que se activa cuando el avión detecta cualquier problema a la hora de realizar una operación. Tras el siniestro de Detroit (hasta el 20 de agosto de 2008, la serie MD-80 se ha visto envuelta en 56 incidentes incluyendo 23 accidentes con pérdida de fuselaje con 1023 fallecimientos. El accidente aéreo ocurrido en Madrid el 20 de agosto del año 2008 tuvo dos claros precedentes: Detroit 1987 y Lanzarote 2007), la comisión estadounidense recomendó que los pilotos del modelo MD-82 debieran revisar antes de cada vuelo si el TOWS funciona. Y así lo hizo saber Boeing el 1 de septiembre de 1987 mediante un "télex a todos los operadores". Pero entonces, Spanair no existía. La nave siniestrada fue adquirida por Spanair a una compañía coreana que tampoco fue avisada específicamente al respecto. 
12. Pero la citada comisión pidió otra cosa más: que los MD-82 dispusieran sin falta de un dispositivo luminoso en la cabina que advirtiera al piloto del estado del TOWS. Boeing dejó de fabricar el modelo siniestrado meses después del accidente de Detroit y ningún dispositivo de este tipo se instaló en los algo más de 1.000 aviones iguales que navegaban entonces por el mundo (el 70\% de ellos, en EE UU).

13. ¿Por qué Spanair no impuso a todos sus pilotos la obligación de revisar el TOWS antes de cada vuelo? ¿Estaba Boeing eximida de instalar esos dispositivos en los MD-82 que ya estaban operativos? De hecho, sí lo hizo en el modelo de avión que sustituyó al MD-82. Muchos de los antiguos MD-82 estaban en manos del Ejército americano. Éstas serán las dos grandes batallas jurídicas de la investigación. Los intereses de Boeing y Spanair son opuestos en esta causa. Por medio están las millonarias indemnizaciones a las víctimas.

\section{III. ¿CONTROVERSIA NACIONAL O CONECTADA CON MÁS PAÍSES?}

14. De las primeras conclusiones del informe interino de las causas del accidente de Spanair, se extraía que fue un error imputable al piloto y al copiloto, fallecidos los dos en el terrible accidente. Pero, profundizando en el asunto, se ve que quizás ese error no fue totalmente imputable a los pilotos, ya que si el sistema de alarma hubiese funcionado correctamente, probablemente la actuación de los pilotos hubiera sido distinta: posiblemente habrían abortado el despegue. Y quién sabe si hoy estaríamos hablando de este fatídico accidente.

15. La compañía norteamericana Boeing, fabricante del MD-82 siniestrado en Barajas el 20 de agosto de 2008, ha reconocido al juez de Madrid que investiga el accidente que no alertó a Spanair de la necesidad de revisar el funcionamiento del sistema de alarma, el TOWS, antes de cada vuelo. "No existe ningún servicio de alerta exclusivo y específico para la aeronave concreta", aclara Boeing al juez, Juan Javier Pérez. El magistrado había pedido a Boeing que le comunicase si había dictado algún "servicio especial de alerta" respecto al MD-82 JK5022, el avión que se estrelló en Barajas.

16. Con independencia de que al piloto fallecido se le olvidara desplegar los flaps y slats y que, además, no revisara el funcionamiento de la alarma, el TOWS, antes de despegar, salta una pregunta: ¿Por qué no sonó la alarma? Fuentes de la investigación no descartan que la tripulación la desconectara indirectamente. Es decir, basta extraer un break circuit (una de caja de fusibles que hay en la misma cabina) y dejaría de sonar la alarma. ¿Para qué? "El avión llevaba una hora de retraso, los pasajeros estaban agobiados de calor y el TOWS emite señales sonoras muy molestas. En el accidente Detroit pasó eso, y parece que habían desconectado el citado circuito", señalan fuentes de la investigación.

17. Por lo tanto, surge una cuestión: ¿Tiene la empresa fabricante de la aeronave algún tipo de responsabilidad? De la instrucción penal se revelaron los distintos problemas técnicos en el McDonnell Douglas MD82 que jugaron un papel esencial en la trágica secuencia de incidentes que confluyeron en el fatal accidente.

18. Lo que aparentemente empezó siendo un caso que no iba a traspasar las fronteras españolas, ya que era un caso en el que se perseguían responsabilidades penales derivadas de hechos íntegramente ocurridos en España, finalmente termina siendo un caso con elementos internacionales y varias conexiones con distintos Estados, al menos dos, España: Estado donde ha ocurrido el daño y EE.UU.: Estado del domicilio del fabricante de la aeronave y lugar de fabricación del avión también. Este asunto acaba por convertirse en un litigio civil 
por daños derivados de los productos y que presenta elementos extranjeros. El Derecho internacional privado entra en acción.

\section{HISTORIA JUDICIAL DEL CASO. LA COMPETENCIA JUDICIAL INTERNACIONAL. ESPECIAL ATENCIÓN A LAS FIGURAS JURÍDICAS DE DERECHO ANGLOSAJÓN: FORUM NON CONVENIENS Y DAÑOS PUNITIVOS}

19. Seis años después de lo ocurrido, y tras un arduo camino judicial mantenido por las familias de las víctimas mortales y algún superviviente de la tragedia, que comenzó con distintas acciones contra la compañía aérea de tipo civil y penal. La presidenta de la Asociación de Víctimas del Accidente del Vuelo JK5022 de Spanair, doña Pilar Vera, ha denunciado el "caos judicial" al se somete a las víctimas de accidentes aéreos en España. La compañía aseguradora ofrece 12,8 millones de euros de los 1.500 millones de dólares (1.129 millones de euros) contemplados en la póliza de la empresa para indemnizar a las víctimas. Seis años después y tras el cierre de la causa penal, la aseguradora Mapfre ha indemnizado al $43 \%$ de las víctimas y perjudicados del accidente con 20,5 millones de euros, y ofrece 12,8 millones para los cerca de 130 afectados restantes que se encuentran dentro de las 42 negociaciones en curso que mantiene la aseguradora. Tras archivarse la causa penal, los afectados han decidido recurrir al Tribunal Europeo de Derechos Humanos de Estrasburgo tras agotar la vía judicial en España, después de que el caso quedara sobreseído por la Audiencia Provincial de Madrid (que levantó la imputación a los dos técnicos juzgados y consideró que su actuación había sido correcta y no constituyó imprudencia). Así las cosas, la Asociación de Afectados del Vuelo JK5022 presentó en marzo de 2014 una demanda ante el Tribunal de Derechos Humanos de Estrasburgo, en la que denuncia "infracciones" contra el Convenio Europeo de Derechos Humanos por parte de la Justicia española en este caso. Y ante este "caos judicial" un amplio grupo de familiares de las victimas decidieron emprender acciones legales contra la empresa norteamericana Boeing (Boeing es una empresa líder mundial de aeronáutica y de defensa, es el mayor fabricante de aviones comerciales y militares, además de uno de los más importantes constructores de equipos aeroespaciales del mundo. Su nombre completo es The Boeing Company y su sede central se encuentra en la ciudad de Chicago. Las fábricas mayores están situadas en los alrededores de la ciudad de Seattle, en el estado de Washington, junto a las costas del Océano Pacífico, como la fábrica de Everett. Boeing absorbió a McDonnell Douglas en el año 1997). Fue entonces cuando un Juez Federal en California, tras asegurar los diferentes procedimientos judiciales, las desestimó en bloque, y aplicó la figura del Derecho anglosajón conocida como Forum Non Conveniens e instó a los demandantes a que llevaran su acción judicial contra el fabricante de la aeronave en España. Y es en España (país donde se produjo el accidente) donde situamos una acción de responsabilidad derivada de daños por productos, en la que concurren elementos internacionales. El Juzgado de Primera Instancia número 2 de Las Palmas de Gran Canaria consideró que la demanda reúne todos los requisitos y se declaró competente para resolverla.

20. Pero, ¿Qué es el Forum Non Conveniens? El Forum Non Conveniens es un mecanismo técnico-jurídico en cuya virtud, los tribunales de un país, pese a disponer en su legislación de un foro de competencia judicial internacional para conocer de un litigio, rechazan entrar a conocer del mismo, por estimar que existe otra "jurisdicción extranjera mejor situada" para conocer de la cuestión. Se trata de una figura jurídica nacida en Derecho 
escocés y propia de países anglosajones como Inglaterra, USA, Canadá, Australia, etc. (vid. un magnífico ejemplo en la sent. CA París 6 marzo 2008 [acción contra cuatro sociedades norteamericanas y decisión del tribunal norteamericano en favor de la competencia de los tribunales franceses en caso derivado de catástrofe aérea] (Carrascosa, 2013: 400). Es en los casos de accidentes de aviación donde coinciden generalmente las condiciones y circunstancias: los demandantes suelen ser extranjeros, normalmente son los familiares de las víctimas de una tragedia aérea que reclaman responsabilidad civil a alguna empresa, o a varias, con domicilio en los Estados Unidos de Norteamérica. Y es cuando se conjugan estas circunstancias, cuando los tribunales norteamericanos suelen utilizar el Forum Non Conveniens, alegando que hay otras jurisdicciones mejor situadas para conocer del asunto, y evadiendo así la aplicación de la Ley norteamericana, debiendo por lo tanto, los demandantes acudir a otra jurisdicción, la cual, muy probablemente acabará por aplicar al asunto su Ley, que quizá resulta más beneficiosa para los demandados, es decir, las empresas norteamericanas. De este modo, el juez norteamericano se libra de juzgar un caso muy grave y además, no quiere juzgar a una empresa norteamericana. Parte de una perspectiva en la que piensa que un juez español va a aplicar Derecho español al fondo del asunto, bien porque aplica su Lex fori siempre (como hacen muchos Estados norteamericanos) bien porque aplica la Lex Loci. Con ello, protege a su empresa, porque una empresa norteamericana que comercializa sus productos en un país con standards de responsabilidad civil inferiores a los standards norteamericanos se sujeta al Derecho de dicho país (España) y paga menos por esa responsabilidad que le tocaría cumplir.

21. La doctrina del Forum Non Conveniens puede tener un gran impacto en la futura sentencia que vaya a dictar el órgano jurisdiccional español. Recientemente, vimos el gran impacto que tuvo esta figura anglosajona en la sentencia de la Audiencia Provincial de Barna de 7 de mayo de 2012, esta sentencia trae causa de un trágico accidente aéreo, y es en este tipo de casos donde se ve un mayor uso de esta figura por parte de los tribunales estadounidenses. La novedad que aporta esta sentencia es, entre otras muchas, ver la posible repercusión que puede tener la aplicación de la figura del Forum Non Conveniens al otro lado del Atlántico para la aplicación de la Ley norteamericana al caso concreto, aunque sea un país europeo el que conozca del asunto.

22. Para que se pueda aplicar la doctrina del Forum Non Conveniens resulta necesario que concurran los siguientes requisitos: $1^{\circ}$ ) El juez debe de ser competente, esto es, ha de existir una norma de competencia previa que le faculte para entrar a conocer del asunto. $2^{\circ}$ ) Debe de haber un foro alternativo al que pueda dirigirse el demandante, extremo este que ha de probar el demandado. $3^{\circ}$ ) Se debe verificar que el segundo tribunal es competente para resolver el litigio, algo que la jurisprudencia norteamericana resuelve condicionando la concesión del Forum Non Conveniens al sometimiento del demandado a la competencia del segundo tribunal. $4^{\circ}$ ) El foro alternativo ha de ser adecuado. Corresponde al tribunal decidir, apreciando los argumentos y pruebas presentadas por las partes y evaluando los intereses públicos y privados en juego, si considera que realmente el foro es adecuado o por el contrario el procedimiento ha de continuar. $5^{\circ}$ ) Finalmente, en caso de que se admita, el tribunal rechaza (dismiss) el conocimiento del asunto si bien bajo el cumplimiento de una serie de condiciones: a) que el demandado se someta a la competencia del segundo tribunal, tal y como se ha señalado anteriormente y; b) que en caso de que el tribunal alternativo decida no entrar a conocer del asunto, el primero retome el mismo. En el análisis de la doctrina del Forum Non Conveniens juega un papel especialmente relevante la valoración que realice el juez del conjunto de factores de interés privado (private interest factor) y de interés público (public interest factors) concurrentes en el litigio. Aunque no existe un 
numerus clausus de tales factores, que deban de ser analizados siempre y en todo litigio, los más relevantes son los siguientes: a) en relación a los factores de interés privado, que afectan a los litigantes cabe incluir el acceso a los medios de prueba, existencia de un proceso obligatorio en caso de no comparecencia del demando; coste del procedimiento, comparecencia de testigos, posibilidad de vista previa, adecuación del proceso a la acción, y todas aquellas cuestiones prácticas que hacen la resolución de un litigio más fácil, rápida y económica. Adicionalmente se puede tener en cuenta la posibilidad de ejecutar o no la sentencia si es que ésta se obtiene así como los obstáculos o ventajas para acceder a un juicio justo. b) Respecto a los factores de interés público, el tribunal debe considerar las dificultades administrativas, tales como la congestión de la justicia. Además no se debería imponer el deber del jurado a los ciudadanos cuando el litigio no tiene relación con la comunidad. Idea esta que se sustenta en el interés local de tener localizados las controversias que se deciden en el propio foro, en tanto que se les aplicará el propio derecho, evitando con ello la aplicación de las normas de conflicto y con ello el Derecho extranjero. Al margen de los intereses públicos y privados que concurran en el caso, existe otro factor determinante para la aplicación del Forum Non Conveniens: que el demandante esté radicado o no en los EE UU. Cuando los demandantes están domiciliados en Estados Unidos y los demandados son extranjeros, existe una presunción favorable sobre la competencia de los tribunales norteamericanos. En el caso inverso, la presunción decae, siguiéndose una línea muy flexible. De tal forma que no se consideran factores determinantes para calificar al foro alternativo como inadecuado: a) ni el hecho de cambio de ley aplicable a no ser que el resultado que aporte sea totalmente insatisfactorio; b) ni la limitación de recursos procesales que existan en el ordenamiento del foro alternativo en relación a los establecidos en el derecho norteamericano. Esta última distinción determinante a la hora de aplicar el Forum Non Conveniens ha sido muy criticada por la doctrina, especialmente en Europa. La razón es obvia: a través de este expediente las empresas norteamericanas quedan inmunes por los hechos acaecidos en el extranjero pero que sin embargo les serían imputables según la ley interna norteamericana. De ahí que pueda afirmarse que una de las premisas que subyace en la alegación del Forum Non Conveniens por parte del demando radicado en EEUU sea la búsqueda de una ley aplicable más beneficiosa (Hernández, 2012: 307-321).

23. Especial mención hay que hacer a los daños punitivos, ya que el mayor temor de la empresa norteamericana es que se los hicieran pagar, al aplicar al supuesto la ley correspondiente norteamericana. Los daños punitivos consisten en una cantidad económica que debe desembolsar el responsable de un daño con la triple finalidad de (a) castigar al responsable (función punitiva-represiva), (b) impedir que se lucre con sus actos antijurídicos (función evitadora del enriquecimiento injusto del infractor) y (c) de disuadir a dicho demandado y a otras personas de que realicen las actividades como las que causaron daños al demandante (función disuasoria-admonitoria). Los daños punitivos constituyen, por tanto, una institución legal diferente a los daños y perjuicios propios del Derecho europeo continental. En efecto, la finalidad de estos daños punitivos no radica en compensar al demandante/víctima por el perjuicio sufrido, sino en castigar una conducta. En consecuencia, en los sistemas jurídicos que admiten estos daños punitivos, el responsable del daño debe satisfacer al demandado-víctima, aparte del importe del perjuicio efectivamente ocasionado, una suma adicional, que suele ser muy elevada, en concepto de tales daños punitivos. Los daños punitivos se regulan y aceptan en el Derecho de la mayor parte de los Estados anglosajones, especialmente, en el Derecho Privado de los distintos States que forman los Estados Unidos de América. En concreto, debe recordarse que los daños punitivos son 
admitidos en cuarenta y seis de los cincuenta States de la Unión. Además, los Compensatory Damages que se recogen en la legislación de dos de estos cuatro States disidentes, -New Hampshire y Washington-, se definen de modo muy amplio de modo que pueden también ser calificados como daños punitivos encubiertos. Nebraska y Michigan son los dos States de la Unión sin auténticos daños punitivos en sus respectivas legislaciones. Estos daños punitivos constituyen una especie de pena privada prevista sólo para castigar actos particularmente dañosos, graves, vejatorios y ofensivos, tales como los daños al medio ambiente, a la salud y a la vida de las personas, y a la seguridad pública (Calvo y Carrascosa, 2014: 1153-1161).

\section{DERECHO APLICABLE Y SU PROBLEMÁTICA APLICACIÓN POR LOS ÓRGANOS JURISDICCIONALES ESPAÑOLES. REGLAMENTO ROMA II}

24. Despejada la cuestión de la competencia judicial internacional, se abre otra incógnita: es preciso aclarar cuál va a ser el Derecho aplicable para resolver la cuestión de la responsabilidad del fabricante del producto. En el ámbito del Derecho Internacional privado europeo encontramos el Reglamento Roma II (Reglamento (CE) nº 864/2007 del Parlamento Europeo y del Consejo de 11 de julio de 2007 relativo a la ley aplicable a las obligaciones extracontractuales), este Reglamento determina la ley aplicable a las obligaciones extracontractuales, incluida la responsabilidad extracontractual derivada de productos defectuosos (artículo 5 Reglamento Roma II). Se deberá comprobar que se cumplen todos los ámbitos de aplicación del Reglamento Roma II: ámbito de aplicación material: a) supuestos relativos a obligaciones extracontractuales y b) supuestos con carácter "internacional". Ámbito de aplicación espacial: se aplica por todas las autoridades de los Estados miembros participantes en el Reglamento Roma II y en el entero territorio de tales Estados miembros. Son Estados miembros participantes todos los Estados miembros de la UE, excepto Dinamarca. El Reino Unido e Irlanda también son participantes, ya que ejercitaron su derecho de opting-in. Ámbito de aplicación personal: carácter erga omnes (artículo 3 Reglamento Roma II). Ámbito de aplicación temporal: es irretroactivo. Se aplica íntegramente a los hechos ocurridos a partir del 11 de enero de 2009 (Calvo et al. 2014: 1094-1098). Por lo tanto, el Reglamento Roma II no estaba en vigor cuando ocurrió la tragedia. El accidente de Spanair se produjo el 20 de agosto del año 2008. En España, la responsabilidad extracontractual por daños derivados de productos defectuosos no se rige ni por Reglamento Roma II ni por el art. 10.9 CC, sino por el Convenio de La Haya de 2 de octubre de 1973 sobre Ley aplicable a la responsabilidad por productos, en vigor desde el 1 de febrero de 1989. Según el art. 28.1 Reglamento Roma II prevalecen sobre el Reglamento, los convenios internacionales anteriores al mismo en que sean parte uno o más Estados miembro y que regulen los conflictos de leyes en materia de obligaciones extracontractuales. Tal es el caso del Convenio de La Haya de 1973(Hernández, 2012: 307-321).

25. Visto esto, debe indicarse que la norma de conflicto aplicable para resolver la incógnita del Derecho aplicable a este supuesto se contiene en el Convenio de la Haya sobre la Ley Aplicable a la responsabilidad por productos defectuosos, firmado en la Haya el 2 de octubre de 1973. Las normas de conflicto que contiene son básicamente tres, con aplicación en cascada:

a) Se aplicará la ley del Estado donde se produjo el daño, si éste es también a) el Estado de residencia habitual de la persona directamente perjudicada, o b) el Estado en el que se encuentre el establecimiento principal de la persona a quien se le imputa la responsabilidad, o 
c) el Estado en cuyo territorio el producto ha sido adquirido por la persona directamente perjudicada (artículo 4).

b) En defecto de lo anterior, se aplicará la ley interna del Estado del Estado de residencia habitual de la persona directamente perjudicada en el caso de que dicho Estado sea también: a) el Estado en el que se encuentra el establecimiento principal de la persona a quien se le imputa la responsabilidad, o b) el Estado en cuyo territorio hubiese sido adquirido el producto por la persona directamente perjudicada (artículo 5).

c) En el caso de que no fuere aplicable alguna de las legislaciones señaladas en los artículos 4 y 5, será aplicable el Derecho interno del Estado en que se halle el establecimiento principal de la persona a quien se le imputa la responsabilidad, a menos que el demandante base su reclamación en el Derecho interno del Estado en cuyo territorio se hubiere producido el daño (artículo 6).

26. Los conceptos que contienen estos preceptos son excesivamente vagos y se deberá de interpretar a los mismos para aclarar, por ejemplo, ¿cuál es el Estado donde se ha producido el daño? ¿Y si ese daño se origina en el lugar donde se produce el evento que provoca directamente el daño a la víctima (accidente), o el lugar donde se produce el hecho generador del daño (lugar de diseño y/o fabricación del producto)? ¿Y la sede principal del fabricante? Si esta sede principal ha variado ¿hay que considerar para ello el momento de diseño y/o fabricación del producto, el momento en el que se produce el "accidente" o el momento en el que se interpone la demanda? ¿Y si el producto se fabrica en fases que tienen lugar en Estados diferentes?

27. Además se habrá de considerar el tipo de daño: ese daño puede ser material o corporal; el tipo de producto, y sobre todo la estrategia de comercialización desarrollada por la empresa que fabrica los productos: no será lo mismo vender un producto autóctono a turistas que visitan el país (por ejemplo: pequeño comerciante que vende quesos en Menorca, y los turistas que visitan Menorca los compran), que fabricar flats y slats (dispositivos de las alas que ayudan a elevar el avión), para aviones que vuelan por todo el mundo. En el artículo 2 del Convenio de la Haya de 1973 se contienen las definiciones de "producto", "daño" y "persona". Por "producto" se entienden los naturales y los industriales, así como los muebles y los inmuebles. El concepto de "daño" hace referencia tanto a los corporales como los patrimoniales ("daño a las personas o bienes, así como la pérdida económica", dice el art. 2.b), quedando excluidos los daños al propio producto. Finalmente, la expresión "persona" alude tanto a las físicas como a las jurídicas (Seuba, 2005:2-28). Hay que destacar también que el Convenio de la Haya de 1973 no requiere para su aplicación que el producto sea defectuoso. Basta que el producto sea el causante del daño.

28. Como puede verse, la aplicación de este o aquel Derecho estatal depende pues de tres factores principales (y según se interpreten éstos): 1) lugar de producción del daño, 2)

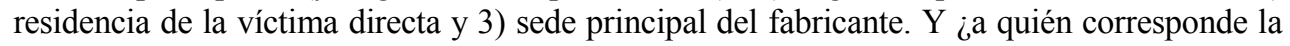
interpretación de estos conceptos vagos? En principio, a la jurisdicción encargada que tenga que aplicar estos términos. Esto puede dar lugar a diferentes interpretaciones, y no hay apenas ejemplos en derecho comparado de cómo se ha llevado a cabo la aplicación de estos criterios.

29. El Derecho Internacional Privado de producción convencional presenta numerosas ventajas: a) Unifican el DIPr. de los Estados parte. b) Son normas con alta calidad técnica. c) Ayudan a modernizar el sistema de DIPr. estatal. Pero también presentan numerosos inconvenientes: a) Carácter limitado de los resultados, por ser el resultado de un consenso entre distintos Estados. b) Errores de aplicación por parte de las autoridades internas. c) 
Diferencias de trato jurídico, puesto que la celebración de convenios internacionales de DIPr. con ciertos Estados y no con otros, crea una diferencia de tratamiento legal entre sujetos de Estados distintos (Calvo et al. 2014: 75-79). Los Convenios hechos por la Conferencia de la Haya de DIPr. carecen de mecanismos para lograr una interpretación uniforme de sus conceptos jurídicos. Lo que es un hándicap y a la vez, un defecto importante de estos Convenios.

30. Según como se interpreten los tres conceptos antes reseñados, la ley aplicable a la responsabilidad civil de Boeing podrá ser, según los casos, la del Estado de la residencia de la víctima, la del lugar del accidente, la del lugar en el que se diseñó y/o fabricó la aeronave, que a su vez esta puede ser: la de la sede principal del fabricante en el momento de la fabricación, en el momento del diseño y/o fabricación, en el momento del accidente o en el momento de la interposición de la demanda. En función de cómo se pronuncien los tribunales españoles al respecto de estos conceptos, se sabrá cuál es la ley aplicable a la acción que se desee ejercer contra la compañía norteamericana Boeing.

31. La aeronave siniestrada en el accidente de Spanair en el aeropuerto de Madrid fue diseñada y fabricada por la desaparecida empresa McDonnell Douglas en Long Beach, California, donde ésta tenía su sede principal. Posteriormente, en 1997, la empresa fue absorbida por The Boeing Company, cuya sede principal en ese momento se encontraba en Seattle, Washington, y actualmente en Chicago, Illinois.

32. Previamente a cualquier accidente, una empresa que fabrica productos que, por definición, van dirigidos a la exportación, y que por lo tanto, se venden y se utilizan en todo el mundo, se cuestiona cuál será la Ley estatal que rige su responsabilidad civil en el caso de daños derivados de sus productos. Son empresas de alcance mundial y con mercados de dimensión mundial. El tipo de daño que pueden causar estos productos es un daño de altísimo alcance, con frecuencia, la muerte. Son productos que se comercializan en todo el planeta, y se utilizan en todo el planeta y en zonas y espacios aéreos situados incluso fuera de toda soberanía estatal. En el caso que nos ocupa se intenta despejar esta incógnita en relación a dos instrumentos legales: a) el Convenio de la Haya sobre la Ley aplicable a la responsabilidad por productos, hecho el 2 de octubre de 1973, y b) el Reglamento Roma II. El Convenio de la Haya se aplica en este supuesto y la Ley que regiría esta responsabilidad sería la de la sede del fabricante.

33. Pero, ¿por qué debe ser aplicable la última conexión de la escalera de puntos de conexión contenida en el Convenio de la Haya de 1973? El artículo 4 del Convenio no sería aplicable. Este precepto señala que la legislación aplicable será el Derecho interno del Estado en cuyo territorio se haya producido el daño, en el caso de que dicho Estado sea también: a) el Estado de residencia habitual de la persona directamente perjudicada (accidente producido en Madrid y residencia habitual de las victimas en España, la mayoría) opino que en este caso, para las víctimas que tuvieran su residencia habitual en España, sería aplicable la Ley española; o b) el Estado en el que se encuentre el establecimiento principal de la persona a quien se le imputa la responsabilidad (esta conexión no concurre porque el Estado donde se produjo el daño es España y el establecimiento del presunto responsable se encontraba en USA) o c) el Estado en cuyo territorio el producto ha sido adquirido por la persona directamente perjudicada (esta conexión tampoco concurre, ya que el producto nunca fue adquirido por los perjudicados directos). Por lo tanto, no concurre ningún punto de conexión del artículo 4 del Convenio de la Haya de 1973, salvo que sean sujetos con residencia habitual en España porque respecto de los mismos sí que es aplicable la Ley española.

34. Tampoco concurre ningún punto de conexión del artículo 5 del mismo Convenio. El artículo 5 establece que: a) si la persona perjudicada reside en el mismo Estado donde se 
halla el establecimiento principal de la persona a quien se le imputa la responsabilidad, dicha Ley es aplicable (tampoco concurre puesto que los perjudicado tenían su residencia habitual en España, la mayoría de ellos, y los presuntos responsables tenían su establecimiento principal en USA); b) si la persona perjudicada reside en el mismo Estado en cuyo territorio se ha adquirido el producto, dicha Ley es aplicable (y volvemos a la conclusión anterior, las víctimas directas nunca adquirieron el producto).

35. Finalmente el juez debería llegar a la conclusión de que sería aplicable para las víctimas sin residencia habitual en España la Ley norteamericana, en virtud del artículo 6 del Convenio de la Haya: la cuestión se regula por el Derecho interno del Estado en donde se halle el establecimiento principal de la persona a quien se le imputa la responsabilidad, o por el Derecho interno del Estado en cuyo territorio se hubiere producido el daño, a elección del demandante. Presuponiendo en este punto, que los familiares de las víctimas elegirían por las distintas ventajas que comporta la primera opción que les ofrece el artículo 6 del Convenio de la Haya de 1973.

36. Desde un punto de vista económico ésta es la opción preferida por las grandes empresas que fabrican productos de comercialización mundial y con alto impacto sobre la salud (fabricantes de aviones, de alimentos, de medicinas...) cuanto más amplio sea el espectro de comercialización internacional de un producto, más posibilidades hay de que se aplique la Ley del país del fabricante. Los datos del caso nos indican que sería la Ley californiana, que es la Ley donde tenía su sede principal la empresa fabricante de la aeronave. En este supuesto se podría dar el mismo razonamiento que llevó al juez español a aplicar la Ley norteamericana en el caso Honeywell. El juez español llegó a aplicar, finalmente, el artículo 6 del Convenio de la Haya de 1973: le da la opción a los actores de ejercitar sus acciones con arreglo al Derecho norteamericano, que es el Derecho interno del Estado donde se halla el establecimiento principal de la persona a la que se le imputa la responsabilidad o por el Derecho interno del Estado en cuyo territorio se hubiere producido el daño, Derecho español (Calvo y Carrascosa, 2014: 1141).

37. Sin embargo, resulta útil cuestionarse acerca de cuál sería la Ley aplicable a esta responsabilidad en el caso de que el Convenio de la Haya de 1973 no fuera aplicable. El Reglamento Roma II, en su artículo 5 contiene la norma de conflicto que señala la Ley aplicable a la responsabilidad civil por daños derivados de los productos: "Sin perjuicio del artículo 4, apartado 2, la ley aplicable a la obligación extracontractual que se derive en caso de daño causado por un producto será: a) la ley del país en el cual la persona perjudicada tuviera su residencia habitual en el momento de producirse el daño, si el producto se comercializó en dicho país, o, en su defecto; b) la ley del país en el que se adquirió el producto, si el producto se comercializó en dicho país, o, en su defecto; c) la ley del país en que se produjo el daño, si el producto se comercializó en dicho país. No obstante, la ley aplicable será la del país en el que tenga su residencia habitual la persona cuya responsabilidad se alega si no podía prever razonablemente la comercialización del producto o de un producto del mismo tipo en el país cuya ley sea aplicable con arreglo a las letras a), b) o c). 2. Si del conjunto de circunstancias se desprende que el hecho dañoso presenta vínculos manifiestamente más estrechos con otro país distinto del indicado en el apartado 1 , se aplicará la ley de este otro país. Un vínculo manifiestamente más estrecho con otro país podría estar basado en una relación preexistente entre las partes, como por ejemplo un contrato, que esté estrechamente vinculada con el hecho dañoso en cuestión." Aunque este artículo 5 del Reglamento Roma II no se aplicaría al supuesto, ya que en este caso se aplicaría el Convenio de la Haya de 1973. La Ley estatal aplicable a la que nos conduciría el 
Reglamento Roma II sería la Ley norteamericana, ya que no se pudo prever razonablemente la comercialización del producto en España, por lo tanto las letras a), b) y c) del artículo 5 del Reglamento Roma II no serían aplicables. El funcionamiento de la regla general que se encuentra contenida en el artículo 4 de Roma II, recoge en su primer apartado la lex loci delicti comissi; en el segundo apartado del referido precepto se incorpora el criterio de la residencia habitual común de las partes; para finalizar, en el artículo 4.3 del Reglamento Roma II se presenta la conexión de los vínculos más estrechos. Aunque en la redacción del texto se parte como regla general de la lex loci delicti comissi de la lectura completa del artículo se deduce un resultado distinto. En efecto, la primera de las conexiones enunciadas se aplicará en realidad en último lugar, tras la no coincidencia de la residencia habitual común de las partes y de que no exista un ordenamiento jurídico con el que el que el hecho dañoso mantenga los vínculos más estrechos (Herranz, 2009). Por lo tanto, en principio la solución desembocaría igualmente en la aplicación del Derecho norteamericano, como ocurría con el Convenio de la Haya de 1973, siempre parcialmente.

\section{CONCLUSIONES}

38. El caso Spanair es un caso interesante porque presenta múltiples perfiles y permite profundizar en aspectos diferentes del DIPr. A continuación se enumeran las conclusiones extraídas de este caso.

39. Primera conclusión. Es de trascendental importancia confeccionar una estrategia de mercado por parte de las empresas fabricantes de productos que se comercializan con carácter planetario. Es esencial que esa estrategia de mercado les permita saber a priori cuál va a ser el órgano jurisdiccional competente para conocer de una posible controversia, y cuál va a ser el Derecho estatal aplicable a la misma. El empresario - fabricante debe asesorarse jurídicamente por expertos en DIPr. y litigación internacional para "limitar el número de países en los que puede ser demandado". Es muy tentador convertir al planeta en un gigantesco pero único mercado (más ventas, más clientes) pero luego llegan las sorpresas: te pueden demandar en países imprevisibles y la responsabilidad civil del fabricante se puede ver sujeta a leyes de imprevisible aplicación.

40. Segunda conclusión. Aunque es una realidad, que en ocasiones es tarea imposible prever donde un producto puede causar un daño. Ante esta incertidumbre previa, dependiendo qué instrumento legal internacional sea aplicable al supuesto, se llegará a una conclusión u otra. En el ámbito de la Ley aplicable en este supuesto, han sido aplicados dos instrumentos legales diferentes: Que conducían finalmente a la aplicación de una misma Ley estatal para dar solución a la controversia: la Ley norteamericana. Siempre de un modo parcial.

41. Tercera conclusión. En el Convenio de la Haya de 1973, las empresas que comercializan productos en todo el mundo están sujetas básicamente a dos reglas: a) Lex loci para las víctimas que tienen su residencia habitual en dicho país. Si una empresa vende productos a destinatarios con residencia habitual en un Estado "1" no se puede extrañar de que la ley de ese Estado "1" sea aplicable a su responsabilidad civil consecuencia de daños derivados de sus productos que perjudican a los que residen habitualmente en un Estado " 1 ": esta regla es lógica y justa; b) Ley de la residencia habitual del fabricante si el daño se produce en un Estado "1" y las víctimas tienen su residencia habitual en otro estado que no sea ese Estado "1", atención: se exige que el producto haya sido comercializado en dicho estado (siempre que la víctima elija litigar con arreglo a dicha ley): esta regla es justa y 
lógica. Quien comercializa en todo el mundo está sujeto a la lex loci, pero sólo respecto de víctimas que tiene su residencia habitual en dicho Estado, para los demás, la empresa está sujeta a la ley de su sede (solución que es muy similar al art. 4.1 Reglamento Roma I: el vendedor vende con arreglo a su propia ley: "el contrato de compraventa de mercaderías se regirá por la ley del país donde el vendedor tenga su residencia habitual", de este modo le ahorra costes). En casos de comercio mundial y víctimas el fabricante está sujeto a la responsabilidad civil fijada en su propia ley. Ojo: el que no comercializa en un país pero resulta que sus productos se difunden en dicho país y allí causan daños, está sujeto a su propia ley de su sede: art. 7 Convenio: por eso es importante dejar claro hacia qué países se quiere dirigir, es decir, comercializar el producto.

42. Cuarta conclusión. El lugar donde se produce el daño es sin duda un importante contacto. Aunque surjan casos en los que este lugar esté situado en un Estado que no tenga ninguna otra conexión con las partes. El artículo 4 del Convenio de la Haya añade tres puntos de conexión que se deben encontrar en ese Estado (donde se ha producido el daño), ya que de lo contrario, la aplicación de su DIPr. podría considerarse arbitraria. Por esta razón este artículo añade uno de esos tres puntos de conexión al Estado que su Derecho se puede hacer aplicable como Estado donde se ha producido el daño.

43. Quinta conclusión. Toda la escala de conexiones del Convenio de la Haya de 1973 depende de qué se entiende por "comercialización". Este será el concepto clave, pero el Convenio no aporta un claro concepto de lo que es la "comercialización". "Comercialización" significa poner en el comercio. El producto debe llegar mediante canales de comercialización al país, para que se pueda aplicar la Ley del país de la residencia habitual del afectado por el daño de un producto (Informe W. L. M. Reese). A veces un producto llega a un país, pero no ha sido "puesto en el comercio de dicho país" por su fabricante. El Convenio de la Haya de 1973 nada dice sobre el momento en el que el producto debe haber estado disponible, a través de los canales de comercialización, en el Estado en cuestión, con la finalidad de hacer que la Ley aplicable cumpla con el requisito de previsibilidad. El requisito se cumpliría en un contexto en la que era razonablemente previsible que el producto se encontrara en el Estado en el momento de la lesión. Si el producto se encontraba allí antes de la lesión, pero no era previsible que siguiera estando allí en el momento en el que se produce la misma, se dejaría de cumplir con el requisito de previsibilidad de esta norma. Todo esto dependerá de las circunstancias propias de cada caso.

44. Sexta conclusión. ¿Era previsible que el producto fabricado por Boeing se encontrara en España en el momento del accidente? Se deberá de atender a las circunstancias concretas de este caso, para saber si la norma que contempla el Convenio de la Haya de 1973 cumple con el objetivo de previsibilidad. Ahora bien: Una empresa que comercia con aviones que vuelan por todo el mundo no se debe extrañar si el daño se produce en España, en EE.UU. o en cualquier parte del mundo. De ahí que la estrategia de comercialización sea fundamental. Prever cuáles serán los órganos jurisdiccionales que conocerán del asunto en caso de controversia, y saber cuál va a ser el Derecho estatal aplicable al mismo.

45. Séptima conclusión. El DIPr. es un instrumento legal de primera magnitud para potenciar el comercio internacional. Sus normas sirven para que las personas y las empresas intercambien recursos, bienes y servicios, para que se muevan más allá de las fronteras y comercien, no para desincentivar el comercio a nivel internacional. De ahí que el DIPr. deba conducir siempre a tribunales cuya competencia internacional sea previsible ex ante por las empresas oferentes que operan a nivel internacional/mundial y a la aplicación de leyes estatales previsibles por las mismas. 
46. Octava conclusión. Desgraciadamente los fallos que presumiblemente desencadenaron en el terrible accidente de Madrid no se han corregido. Y se debería de avanzar hacia una justicia preventiva y no reactiva. Esto significa que si la solución no llega por vía del Derecho Público (por ejemplo: prohibición a Boeing de vender aviones a España o de que sus aviones sobrevuelen España), debe llegar por vía del Derecho Privado. Esto se traduce en un Derecho Internacional Privado rápido y efectivo que condene a Boeing a pagar por los daños causados.

\section{BILIOGRAFÍA}

CALVO CARAVACA, A. L. y CARRASCOSA GONZÁLEZ, J. (2014). Derecho internacional privado, vol. I. Granada: Comares.

CARRASCOSA GONZÁLEZ, J. (2013). "Daños punitivos. Aspectos de Derecho internacional privado español y europeo" En M. J. Herrador Guardia (coord.) Derecho de Daños. Madrid: Aranzadi, pp. 383464.

HERNÁNDEZ RODRÍGUEZ, A. (2012). “Accidentes aéreos y forum non conveniens. Algunas cuestiones en torno al asunto Honeywell en España", CDT, octubre, vol. 4 (2): 307-321.

HERRANZ BALLESTEROS, M. (2009). "El Reglamento 864/2007 de 11 de julio, relativo a la Ley aplicable a las obligaciones extracontractuales (Roma II)" En: Curso virtual. Un estudio sistemático del espacio judicial europeo en materia civil y mercantil. Consejo General del Poder Judicial. Escuela Judicial. Red Europea de Formación Judicial (REFJ).

REESE, W. (1974). "Explanatory Report on the 1973 Hague Products Liability Convention", HCCH, pp. 1-34. En: www.hcch.net/index_en.php?act=publications.details\&pid=2945\&dtid=3

SEUBA TORREBLANCA, J. C. (2005). "Derecho de daños y Derecho Internacional Privado: algunas cuestiones sobre la legislación aplicable y la propuesta de Reglamento "Roma II". Barcelona: Universitat Pompeu Fabra, en www.indret.com, pp. 2-28.

\section{Breve currículo:}

\section{Isabel Lorente Martínez}

Licenciada en Derecho por la Universidad de Murcia y Máster universitario en investigación avanzada y especializada en Derecho. Doctoranda en Derecho, Área de DIPr en la Universidad de Murcia. Abogada del ICAMUR, colegiada ejerciente $\mathrm{n}^{\circ}$ 6219. Publicaciones: $C D T$, vol. 4, $\mathrm{n}^{\circ} 1$ (2012). "Lugar del hecho dañoso y obligaciones extracontractuales. La sentencia del TJUE de 25 de octubre de 2011 y el coste de la litigación internacional en Internet". $C D T$, vol. 6, n¹ (2014). "Protección de los derechos sobre bienes inmateriales ofertados en Internet". CDT, vol. 6, no2 (2014). "Daños causados por los productos y competencia judicial internacional en la unión europea”. CDT, vol. 7, nº1 (2015). "Los derechos sucesorios del cónyuge viudo en Derecho Internacional Privado: la Sentencia del Tribunal Supremo de 28 abril 2014". CDT, vol. 7, nº (2015). "Convenio de Roma 1980 y Reglamento Roma I. Ley aplicable a las obligaciones contractuales. El contrato de transporte de mercancías y el Tribunal de Justicia de la Unión Europea” 